\title{
Desain Rak Display Untuk Penerbit Zifatama
}

\author{
Omar Mukhtar ${ }^{1 *}$,Faza Wahmuda² \\ ${ }^{1,2}$ Jurusan Desain Produk, Institut Teknologi Adhi Tama Surabaya, Surabaya, Indonesia
}

\begin{tabular}{l|l|l} 
Received: August 2021 & Acepted: September 2021 & Published: October 2021
\end{tabular}

\begin{abstract}
The low interest of people in reading has closed several book publishers as their books were not in demand. Furthermore, there are some publishers who sell their books only for private users such as Zifatama book publisher in Sidoarjo. If this publisher wants to put their books at big book shops, it will get very high charge of tax. This fact has underpinned the researcher to design a portable shelf specifically for Zifatama book publisher so that it can sell the books in the interior events such as seminar, workshop, and training. To design the display shelf, the researcher employed mix method by observing various places related to display shelves and interviewing the head of Zifatama publisher. Those methods aimed to ease the researcher in developing the product through some analyses regarding the needs, activity, display product types, product placement, design style, shape, system, color, technology of information media, material, ergonomics, and product dimension. The final result obtains a product of display shelf having design concepts of informative and modern minimalist which is stackable to ease the publisher bringing it during an interior event. In addition, this display shelf presents information on Zifatama Publisher books to users.
\end{abstract}

Key words: book, display shelf, publisher, Zifatama

\begin{abstract}
Abstrak
Rendahnya minat baca membuat berberapa penerbit buku harus gulung tikar karena buku terbitannya tidak laku, Bahkan ada yang memilih untuk menjual buku hanya untuk kalangan penulisnya saja salah satunya adalah penerbit buku Zifatama di Sidoarjo, dikarenakan jika menaruh buku terbitannya di toko buku besar yang masih bertahan, maka pajaknya akan sangat tinggi, maka terciptalah ide baru dan inovasi yakni diciptakannya Desain Rak Portable khusus untuk buku penerbit Zifatama agar bisa menjual bukunya di acara berinterior seperti seminar, workshop dan pelatihan. Metode penelitian yang di gunakan untuk melakukan perancangan Rak Display ini menggunakan mix method dengan mengobservasi berbagai tempat yang berhubungan dengan Rak Display dan melakukan wawancara dengan pimpian Penerbit Zifatama, Metode yang digunakan bertujuan untuk memudahkan peneliti dalam pembuatan produk yang kemudian dianalisis menggunakan analisis kebutuhan, analisis aktivitas, analisis jenis-jenis produk display, analisis penempatan produk, analisis gaya desain, analisis bentuk, analisis sistem, analisis warna, analisis teknologi media informasi, analisis material, analisis ergonomi dan analisis dimensi produk. Didapatkan dari hasil akhir, produk dengan konsep desain informatif dan modern minimalis, Rak Display ini dapat dibongkar pasang yang memudahkan penerbit dapat membawa Rak ini ke acara berinterior, selain itu pada Rak Display ini terdapat Media Digital Informasi menampilkan informasi buku Penerbit Zifatama yang di display maupun bukubuku Penerbit Zifatama lainnya kepada pengguna.
\end{abstract}

Kata kunci: buku, penerbit, rak display, Zifatama

\section{Pendahuluan}

Membaca adalah salah satu cara untuk mendapatkan informasi dan pengetahuan dari sesuatu yang ditulis. Semakin banyak membaca maka akan semakin banyak pula informasi yang dapatkan, membaca buku dapat membuka wawasan yang sangat membantu di kehidupan, membaca buku juga merupakan suatu cara untuk menghargai hasil karya orang lain. Namun sangat disayangkan, pada zaman sekarang ini, amat jarang ditemukan kegemaran dalam membaca. Kebanyakan dari masyarakat kini disibukkan dengan traveling atau lebih memilih

\footnotetext{
* Corresponding author e-mail : zayyan613@gmail.com, add author e-mail : faza.despro@itats.ac.id
} 
bermain game dirumah, minat baca sekarang ini sangatlah rendah. Padahal, banyak manfaat yang dapat diperoleh dari membaca. (kompasania.com) [1]. Dari data Perpustakaan Nasional tahun 2017, frekuensi membaca orang Indonesia rata-rata hanya tiga sampai empat kali per minggu. Sementara jumlah buku yang dibaca rata-rata hanya lima hingga sembilan buku per tahun (cnn.com) [2] . Hal ini membuat berberapa penerbit buku harus gulung tikar karena buku terbitannya tidak laku, contohnya seperti toko buku gramedia di Mataram (lombokpost.jawapos.com) dan di Majalengka yang kini sepi pengunjung padahal posisinya berada di sebelah kampus terbesar di Majalengka (daerah.sidonews.com) [3] berberapa penerbit buku berinisiatif untuk menjual buku terbitannya di swalayan atau di acara seminar dan pameran. Bahkan ada yang memilih untuk menjual buku hanya untuk kalangan penulisnya saja salah satunya adalah penerbit buku Zifatama di Sidoarjo, dikarenakan jika menaruh buku terbitannya di toko buku besar yang masih bertahan, maka pajaknya akan sangat tinggi. Karena keuntungannya sedikit, biaya operasionalnya banyak dan biaya menitipnya tinggi membuat keuntungan yang didapat Zifatama sedikit, maka terciptalah ide baru dan inovasi yakni menciptakan peluang untuk menarik minat konsumen dengan diciptakannya Desain Rak Portable khusus untuk buku penerbit Zifatama yang gunanya diperuntukan untuk bisa di bawa di ruang berinterior dan bisa di bongkar pasang (Knock down) sehingga penerbit Zifatama bisa menjual bukunya seperti di seminar, workshop dan pelatihan sebagai solusi agar buku yang dijual laku dan minat baca meningkat.

\section{Tinjauan Pustaka}

Sebelum melakukan penelitian mengenai Desain Rak buku terbitan penerbit Zifatama, peneliti terlebih dahulu melakukan tinjauan pustaka. Tinjauan pustaka yang dilakukan peneliti adalah melakukan tinjauan dengan penelitian sebelumnya yang sejenis atau terkait dengan penelitian yang akan dilakukan oleh peneliti. Berikut adalah beberapa penelitian sejenis dan terkait yang peneliti jadikan acuan untuk melakukan penelitian ini:

\subsection{Desain Display Media Interaktif Untuk Museum Lumajang Berbasis Augmented Reality dan Interaksi Gerak Tangan dengan Konsep Futuristik dan Dinasmis}

Penelitian yang dilakukan oleh Dimas Nugroho (2019) mahasiswa Desain Produk FADP ITS (Institut Teknologi Sepuluh November) Surabaya dengan judul penelitian "Desain Display Media Interaktif Untuk Museum Lumajang Berbasis Augmented Reality dan Interaksi Gerak Tangan dengan Konsep Futuristik dan Dinasmis" [4]. Augmented Reality adalah teknologi yang menggabungkan benda maya 2 Dimensi ataupun 3 Dimensi kedalam sebuah lingkungan nyata 3 Dimensi lalu memproyeksikan benda-benda maya tersebut dalam waktu nyata. Manfaat dari penelitian tersebut yaitu bantuan Augmented Reality pada Display dapat meningkatkan user experience/pengalaman yang berbeda

\subsection{Desain Produk Display Untuk Penyajian Alat Perkakas di Swalayan Arga Bangunan}

Penelitian yang dilakukan oleh Wahyu Himawan (2019) mahasiswa Desain Produk FADP ITATS (Institut Teknologi Adhi Tama Surabaya) dengan judul penelitian "Desain Produk Display Untuk Penyajian Alat Perkakas di Swalayan Arga Bangunan" [5]. Teknologi Holographic adalah teknologi yang terbentuk dari perpaduan 2 sinar cahaya yang koheren dan membentuk suatu informasi optic berupa suatu gambar Manfaat dari penelitian tersebut yaitu bantuan Teknologi Holographic pada Display dapat membantu konsumen di Arga bangunan dalam mencari Informasi dan solusi dari terbatas Pramuniaga di Arga bangunan

\section{Metodelogi Penelitian}

Metodologi yang digunakan penelitian ini menggunakan kombinasi atau lebih dikenal dengan mixed method, yaitu gabungan antara penelitian kualitatif dan penelitian kuantitatif, Sugiyono (2013:19) menyebutkan bahwa metode penelitian kombinasi ini menggabungkan antara metode penelitian kualitatif dan metode kuantitatif untuk digunakan secara bersama-sama dalam suatu kegiatan penelitian sehingga diperoleh data yang lebih komperhensif, reliabel dan obyektif [6]. Objek penelitian yakni rak buku di 4 tempat; 1. Toko buku Togamas Diponegoro di Jl. Diponegoro No.93, Darmo, Kec. Wonokromo, Surabaya pada 27 Juni 2021 yakni tempat dijualnya buku terbitan Zifatama, 2. Di Dekesda Art Center saat pameran LAF (Liter Art Festival) pada 19 Juni 2021 yakni tempat dijualnya buku terbitan Embrio sebagai pembanding, 3. Toko buku Gramedia di Taman Aloha No.2, Dusun Ketapang, Sidoarjo pada 2 November 2020 sebagai observasi pendukung 4. Toko buku Mitra Media 
di Jl. Taruna No.102 pada 8 Desember 2020 sebagai observasi pendukung. Wawancara kepada 1.Pimpinan penerbit Zifatama, pada 24 Desember 2020 di kantor penerbit Zifatama, data yang didapat adalah spesifikasi buku terbitan Zifatama dan kebutuhan dari Zifatama jika rancangan dibuat 2.Pimpinan penerbit Embrio, pada 16 Januari 2020 di rumah pimpinan penerbit Embrio, data yang didapat adalah spesifikasi buku terbitan Embrio dan kebutuhan dari Embrio jika rancangan dibuat. Kuisoner dilakukan sebagai penilaian mengenai rancangan yang akan dibuat, pengambilan data kuisoner dilakukan dengan cara membagikan kuisoner kepada para pengunjung di Toko buku. Kuisoner dibagikan ke 30 orang dengan kriteria umur 15-40 tahun, data yang didapat adalah mengenai pendapat responden mengenai rancangan yang akan dibuat. Dokumentasi Pengambilan data dengan cara mendokumentasikan setiap bagian dari penelitian yang dilakukan saat pencarian data yang akan dilakukan di Toko buku. Kemudian melakukan analisis kebutuhan, analisis aktivitas, analisis jenis-jenis produk display, analisis penempatan produk, analisis gaya desain, analisis bentuk, analisis sistem, analisis warna, analisis teknologi media informasi, analisis material, analisis ergonomi dan analisis dimensi produk. Berikut adalah bagan penelitian yang akan dilakukan.

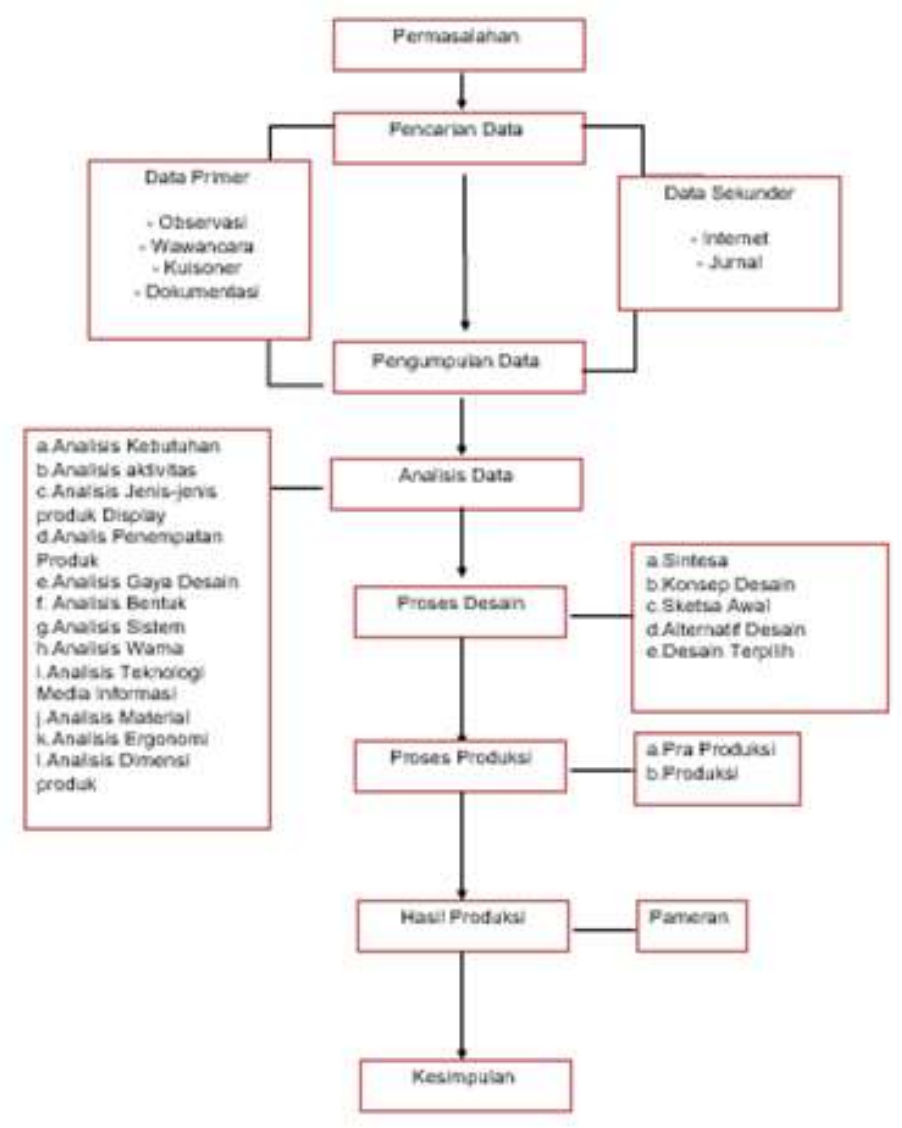

Gambar 1 Bagan penelitian (Sumber: dokumen pribadi)

\section{Hasil dan Pembahasan}

\subsection{Hasil Observasi}

Hasil Observasi di Toko Buku Togamas Diponegoro yang merupakan tempat diterbitkannya buku Zifatama, Pameran Dekesda, Toko Buku Gramedia, Toko Buku Mitra Media dengan tujuan mengolah data menjadi informasi yang bisa dipahami untuk menjawab masalah yang berhubungan dengan penelitian yang dilakukan: 
Omar Mukhtar, Faza Wahmuda

Desain Rak Display Untuk Penerbit Zifatama

\begin{tabular}{|c|c|c|c|c|c|c|}
\hline No. & Aktivitas & Togamas Diponegoro & $\begin{array}{c}\text { Pameran Dekesdas } \\
\text { Art Center }\end{array}$ & $\begin{array}{c}\text { Gramedia Taman } \\
\text { Aloha }\end{array}$ & Mitra Media & Analisis \\
\hline 1. & Konsumen datang ke toko & $\begin{array}{l}\text { Saat memasuki pintu } \\
\text { masuk konsumen } \\
\text { disajikan buku }\end{array}$ & $\begin{array}{l}\text { Saat memasuki pintu } \\
\text { masuk terdapat } \\
\text { standing banner } \\
\text { menginformasikan } \\
\text { keberadaan penerbit }\end{array}$ & $\begin{array}{c}\text { Saat memasuki pintu } \\
\text { masuk tidak disajikan } \\
\text { apa-apa }\end{array}$ & $\begin{array}{c}\text { Saat memasuki pintu } \\
\text { masuk tidak disajikan } \\
\text { buku tapi alat tulis }\end{array}$ & $\begin{array}{c}\text { Gramedia Togamas } \\
\text { Diponegoro menyajikan } \\
\text { buku dipintu masuk } \\
\text { sedangkan Gramedia } \\
\text { taman Aloha tidak } \\
\text { menyajikan apa-apa }\end{array}$ \\
\hline 2. & Konsumen melihat buku & $\begin{array}{l}\text { Terdapat petunjuk dan } \\
\text { informasi jenis-jenis } \\
\text { buku yang ditempelkan } \\
\text { di rak }\end{array}$ & $\begin{array}{l}\text { Terdapat petunjuk } \\
\text { jenis-jenis buku di } \\
\text { standing banner }\end{array}$ & $\begin{array}{c}\text { Tidak terdapat } \\
\text { petunjuk dan dan } \\
\text { informasi jenis-jenis } \\
\text { buku }\end{array}$ & $\begin{array}{l}\text { Terdapat petunjuk dan } \\
\text { informasi jenis-jenis } \\
\text { buku yang ditempelkan } \\
\text { di rak }\end{array}$ & $\begin{array}{c}\text { Di Togamas Diponegoro } \\
\text {,Mitra media dan pameran } \\
\text { Dekesda terdapat petunjuk } \\
\text { jenis-jenis buku }\end{array}$ \\
\hline 3. & $\begin{array}{l}\text { Konsumen membaca } \\
\text { Informasi buku }\end{array}$ & $\begin{array}{l}\text { Terdapat Informasi jenis } \\
\text { buku dan promosi sesuai } \\
\text { genre buku }\end{array}$ & $\begin{array}{c}\text { Tidak ada review atau } \\
\text { informasi buku yang } \\
\text { dijual }\end{array}$ & $\begin{array}{l}\text { Informasi hanya } \\
\text { berupa harga buku }\end{array}$ & $\begin{array}{c}\text { Tidak ada review atau } \\
\text { informasi buku yang } \\
\text { dijual }\end{array}$ & $\begin{array}{l}\text { Togamas Diponegoro } \\
\text { memiliki berbagai cara } \\
\text { untuk memberikan } \\
\text { konsumen informasi buku } \\
\text { yang diinginkan/dicari }\end{array}$ \\
\hline 4. & $\begin{array}{l}\text { Konsumen membayar } \\
\text { buku }\end{array}$ & $\begin{array}{c}\text { Lokasi kasir berada di } \\
\text { pintu masuk dan keluar }\end{array}$ & $\begin{array}{l}\text { Konsumen membayar } \\
\text { ditempat di Stand }\end{array}$ & $\begin{array}{c}\text { Lokasi kasir agak } \\
\text { jauh dari pintu masuk } \\
\text { dan keluar }\end{array}$ & $\begin{array}{l}\text { Lokasi kasir berada di } \\
\text { pintu masuk dan keluar }\end{array}$ & $\begin{array}{l}\text { Togamas Diponegoro dan } \\
\text { Mitra media yang letak } \\
\text { kasimya tepat di pintu } \\
\text { masuk dan keluar }\end{array}$ \\
\hline
\end{tabular}

Gambar 2 Hasil observasi di 4 toko (Sumber: dokumen pribadi)

\subsection{Hasil Kuisoner}

Kuisoner disebar di 2 lokasi yakni dekat toko buku Gramedia Taman Aloha dan toko buku Mitra media, Kuisoner tersebut disebarkan dan diisi oleh 30 Responden yakni 15 Pria dan 15 Wanita dengan kisaran umur 15-30 tahun, untuk menjadi acuan dalam perancangan Desain alternatif yang akan dibuat.

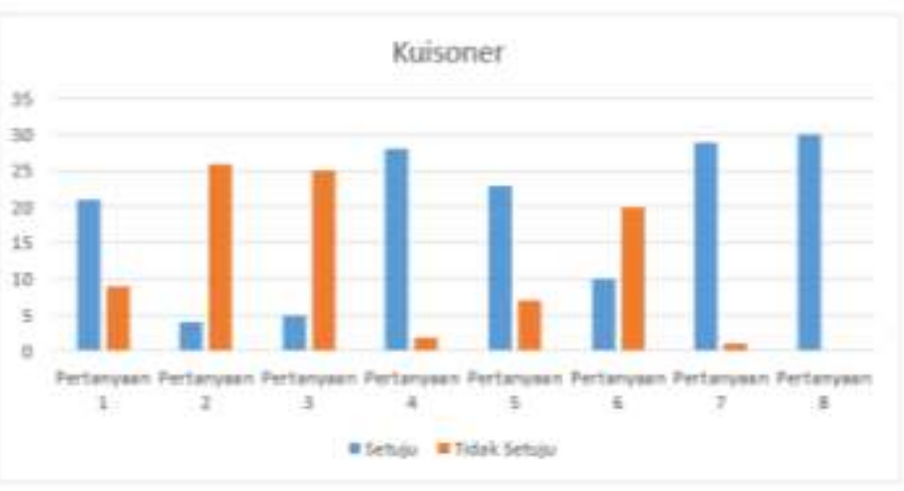

Gambar 3 grafik total kuisoner (Sumber: dokumen pribadi)

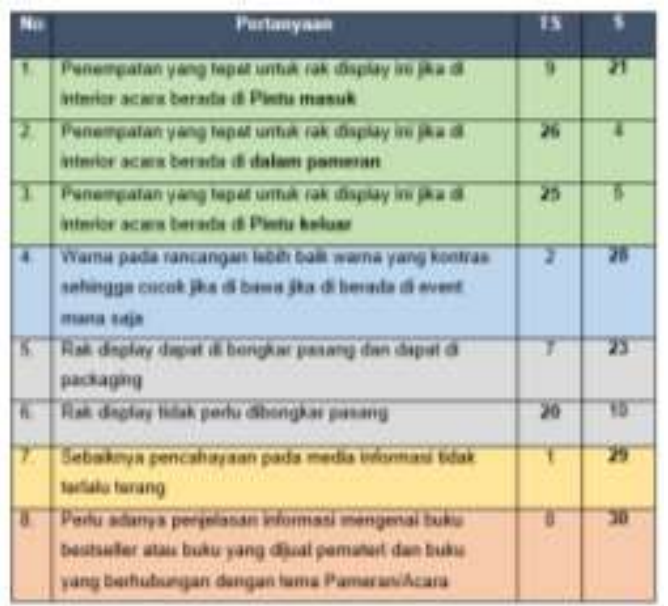

Gambar 4 Hasil Kuisoner (Sumber: dokumen pribadi) 


\subsection{Hasil Wawancara}

Berikut Hasil Wawancara dengan Pimpinan mengenai produk lainnya dan promosi Penerbit Zifatama

Tabel 2 hasil wawancara dengan pimpinan Zifatama (Sumber: dokumen pribadi)

\begin{tabular}{|c|c|c|}
\hline No. & Kebutuhan & Analisis \\
\hline 1. & Dibutuhkan Display Digital & $\begin{array}{l}\text { Dibuatnya Media Digital Informasi sebagai pemberi info } \\
\text { kepada pengguna }\end{array}$ \\
\hline 2. & $\begin{array}{l}\text { Bahan yang digunakan pada rancangan } \\
\text { yakni kayu }\end{array}$ & Material utama yang digunakan adalah kayu \\
\hline 3. & $\begin{array}{l}\text { Konsumen Zifatama yakni Dosen dan } \\
\text { Guru }\end{array}$ & $\begin{array}{l}\text { Pada rancangan akan dibuat menyesuaikan segmentasi Zifatama } \\
\text { dari segi warna maupun bentuk }\end{array}$ \\
\hline 4. & $\begin{array}{l}\text { Zifatama juga menjual buku digital di } \\
\text { google playbook }\end{array}$ & $\begin{array}{l}\text { Dibuatnya informasi buku zifatama yang di google playbook } \\
\text { pada Media Digital Informasi }\end{array}$ \\
\hline 5. & Promosi menggunakan media sosial & $\begin{array}{l}\text { Dicantumkan media sosial zifatama pada Media Digital } \\
\text { Informasi }\end{array}$ \\
\hline 6. & Perlunya Informasi buku yang disajikan & $\begin{array}{l}\text { Dibuatnya media digital informasi pada mengenai buku yang } \\
\text { disajikan }\end{array}$ \\
\hline 7. & $\begin{array}{l}\text { Belum terpikirkan menjual bukunya } \\
\text { dipameran }\end{array}$ & Dibuatnya Rak Display yang dapat dibawa ke berbagai acara \\
\hline 8. & $\begin{array}{l}\text { Diberikannya informasi mengenai acara } \\
\text { seminar/workshop yang diadakan }\end{array}$ & Dicantumkan informasi acara pada Media Digital Informasi \\
\hline
\end{tabular}

\subsection{Analisis Kebutuhan desain}

Hasil analisis kebutuhan yang diambil dari hasil wawancara :

Dibuatnya Media Digital Informasi sebagai pemberi info kepada pengguna, Material utama yang digunakan adalah kayu, Pada rancangan akan dibuat menyesuaikan segmentasi Zifatama dari segi warna maupun bentuk, Dibuatnya informasi buku zifatama yang di google playbook pada Media Digital Informasi, Dicantumkan media sosial zifatama pada Media Digital Informasi, Dibuatnya media digital informasi pada mengenai buku yang disajikan, Dibuatnya Rak Display yang dapat dibawa ke berbagai acara, Dicantumkan informasi acara pada Media Digital Informasi

\subsection{Analisis Aktivitas}

Hasil analisis aktivitas berdasarkan Aktivitas di Toko Buku Togamas Diponegoro, Pameran Dekesdas Art Center, Gramedia Aloha, Mitra Media :

Dibutuhkannya Informasi mengenai Buku yang disajikan, Informasi mengenai penjualan Buku digital di Google Playbook, Informasi mengenai acara seminar/workshop berhubungan dengan buku yang disajikan

\subsection{Analisis Jenis produk display}

Dari hasil analisis jenis produk Display, maka jenis Display yang akan diterapkan pada produk rancangan adalah Impulse Display dimana hanya buku laris dan buku laku yang ditempatkan sehingga sesuai jika diletakan ditempat yang strategis seperti depan pintu masuk toko buku atau depan lobby acara seminar dan workshop

\subsection{Analisis penempatan produk}

Analisis Penempatan produk digunakan untuk menentukan ukuran pada Rak Display agar buku yang di displaykan dapat diletakan berdasarkan hasil observasi studi kasus dan pembanding dengan melihat kategori buku terlaris dan buku laku sebagai penempatan jenis buku tersebut

Tabel 3 Penempatan produk (Sumber: dokumen pribadi)

\begin{tabular}{lll}
\hline No. & Kategori & Keterangan \\
\hline 1. & Buku Laris & - Seluruh buku yang diterbitkan Zifatama berukuran $15.5 \mathrm{x}$ \\
& (Buku refrensi dan buku ajar dosen) & $23 \mathrm{~cm}$ \\
\hline 2. & $\begin{array}{l}\text { Buku Laku } \\
\text { (Buku pelajaran dan buku novel) }\end{array}$ & \\
\hline
\end{tabular}


Dari hasil diatas, maka peletakan buku pada Rak Display untuk Penerbit Zifatama terbagi menjadi berberapa bagian, yakni :
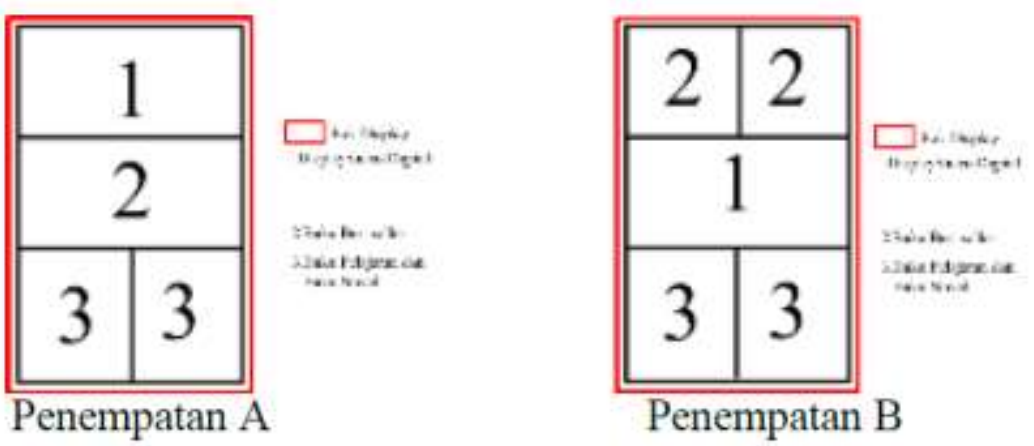

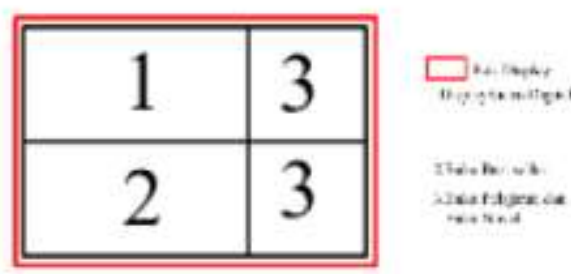

Penempatan C

Gambar 5 Peletakan buku pada rak display (Sumber: dokumen pribadi)

Dari hasil analisis penempatan, pertimbangan dilakukan berdasarkan kebutuhan, kekurangan dari pembentukan rancangan Rak Display untuk penyajian penerbit Zifatama, maka jenis penempatan yang akan digunakan adalah jenis penempatan A. Pada tingkat paling atas akan berupa Display video digital yang berisi informasi buku yang disajikan dan informasi buku lainnya yang Zifatama jual di Google Playbook. Untuk tingkat yang ke 2 akan ditempatkan Buku Laris yang buku refrensi dan ajar dosen, untuk tingkat 3 yang paling bawah akan ditempatkan buku laku yakni buku pelajaran dan novel

\subsection{Analisis Gaya Desain}

Hasil analisis gaya desain, gaya minimalis modern akan digunakan pada rancangan, karena sesuai dengan segmentasi konsumen Zifatama yakni Guru dan Dosen dimana keduanya yakni Zifatama dan para konsumen bergerak dibidang pendidikan, maka pada rancangan dibuat cukup sederhana dan tidak menonjol dan rak display yang harus dapat menghemat tempat dapat mendukung gaya desain tersebut

\subsection{Analisis Bentuk}

Hasil analisis bentuk yang digunakan untuk Rak Display adalah Bentuk box portrait akan lebih dapat memberi pesan komunikatif dalam penyampaian informasi

\subsection{Analisis Sistem}

Dari hasil analisis sistem, akan digunakan sistem knockdown pada rak display yang dapat dilepas pasang dan juga dapat menghemat tempat ketika digunakan

\subsection{Analisis Warna}

Dari hasil analisis warna tentang psikologi warna, maka Warna yang digunakan untuk Rak Display sesuai dengan warna desain Rak Display yakni :

1.Abu-abu : Peneliti memutuskan menggunakan warna utama yakni abu-abu karena berdasarkan wawancara segmentasi pasar Zifatama yakni guru dan dosen yaitu orang tua yang hidupnya sederhana dan modern gaya hidupnya

2.Hitam : Peneliti memutuskan menggunakan warna hitam sebagai warna pendukung karena warna ini memiliki arti psikologi elit dan elegan sehingga dapat memberikan kesan yang mewah pada pengguna

\subsection{Analisis Teknologi Media Informasi}

Dari hasil analisis teknologi, teknologi yang digunakan adalah Liquid Crystal Display dengan medianya yakni Monitor, Kebutuhannya berupa informasi promo dan informasi buku menggunakan LCD di rujuk dari analisis kebutuhan karena yang dibutuhkan yakni informasi mengenai promo dan informasi buku bukan presentasi bentuk bukunya maka yang dibutuhkan adalah infografis 


\subsection{Analisis Material}

\section{Analisis Material Struktur}

Dari hasil analisis material struktur, maka akan digunakan Multiplek sebagai material utamanya dan aklirik sebagai material pendukung untuk menunjang estetika dan untuk kerangkanya menggunakan Aluminium

\section{Analisis Finishing}

Dari hasil analisis maka finishing pada produk yang tepat adalah cat duko karena tidak cepat pudar dan membuat rak jadi awet

\subsection{Analisis Ergonomi}

Analisis Ergonomi yang akan diterapkan pada Rak Display yakni hal-hal yang berhubungan dengan keindahan, kenyamanan melihat dan sebagainya, namun berberapa poin yang harus diperhatikan dan dapat dimaksimalkan pada Rak Display antara lain :

Pencahayaan yang berpengaruh pada tampilan dari Rak Display yaitu video animasi digitalnya. Agar mempermudah ketika Rak Display dipindahkan ketika sudah dibongkar maka pada kaki Rak dimanfaatkan menjadi bagian storage ketika rak sudah di bongkar. Berdasarkan data literatur kemiringan vertikal direkomendasikan $15^{\circ}-45^{\circ}$ menyesuaikan pandangan horizontal mata, maka akan diambil yang terendah yakni $15^{\circ}$ [7].

\subsection{Konsep Desain}

konsep yang akan diterapkan pada rancangan ini adalah Informatif dan minimalis, yang dimaksud Informatif dan minimalis adalah:

a.Informatif yakni memberikan informasi mengenai buku Zifatama

b.Minimalis modern yakni desain yang lebih efisien dan efektif melalui kesederhanaan dalam bentuk, ruang, material, detil dan warna. (www.dekoruma.com) [8].

\subsection{Sketsa Awal}

Sketsa awal dari Rak Display Portable. Dalam pembuatan sketsa terdapat proses-proses transformasi sketsa-sketsa untuk menemukan rancangan yang sesuai. Berikut, gambar sketsa awal Rak Display Portable.

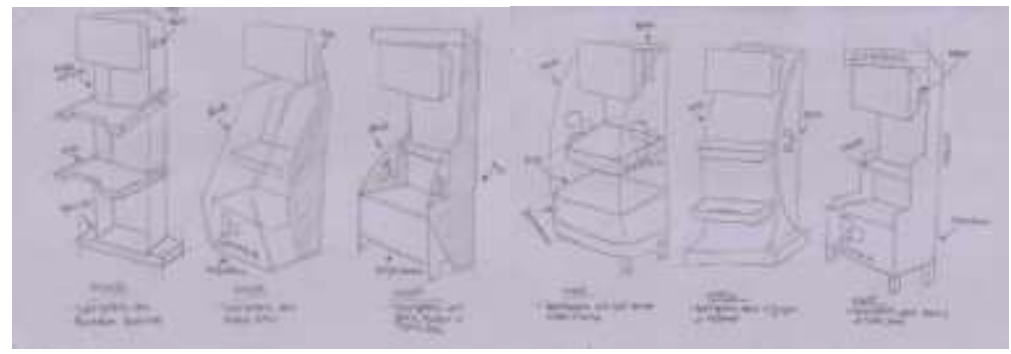

Gambar 6 Gambar sketsa awal (Sumber : dokumen pribadi)

\subsection{Alternatif Desain}

Berikut adalah Alternatif desain yang dibuat yang kemudian akan dipilih Pimpinan Penerbit Zifatama sehingga dapat dibuat rancangan desainnya: 


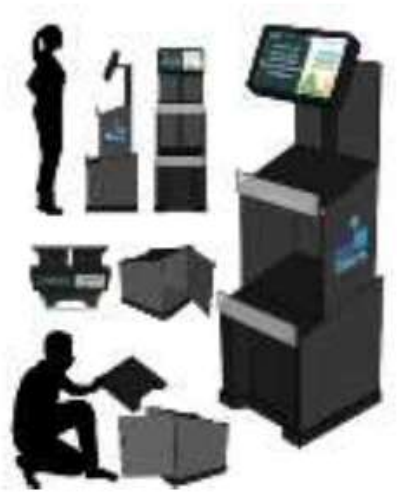

Alternatif Desain 1

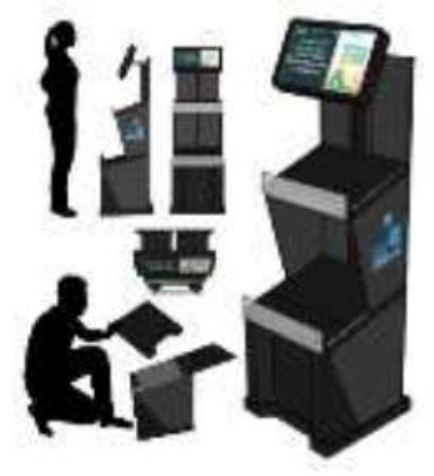

Alternatif Desain 2

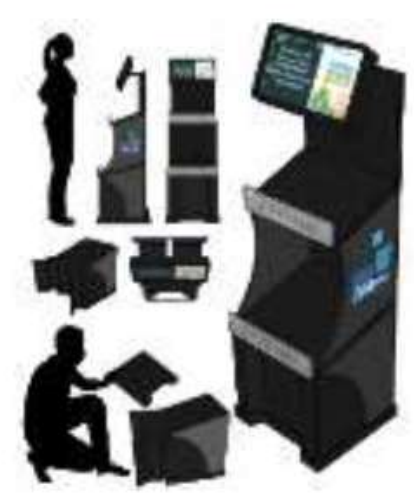

Alternatif Desain 3

Gambar 7 Alternatif desain 1, 2 dan 3 (Sumber : dokumen pribadi)

\subsection{Desain Terpilih}

Alternatif Desain yang dibuat diserahkan kepada pimpinan Penerbit Zifatama sebagai Studi kasus utama pada penelitian ini, penyerahan Alternatif Desain dilakukan pada 14 April 2021 di kantor Penerbit Zifatama, Pada Alternatif Desain yang dibuat penulis, Pimpinan Penerbit Zifatama memilih Alternatif Desain ke 3, tidak ada masukan dari pimpinan penerbit Zifatama, saat ditanya alasan kenapa pimpinan Zifatama memilih Alternatif 3. menurut pimpinan Penerbit Zifatama Desain yang dibuat sudah cukup memenuhi semua kebutuhan Penerbit Zifatama yang ada di wawancara. Pimpinan Penerbit Zifatama menyampaikan untuk tidak perlu ditambahkan atau dirubah rancangan yang dipilih tersebut.

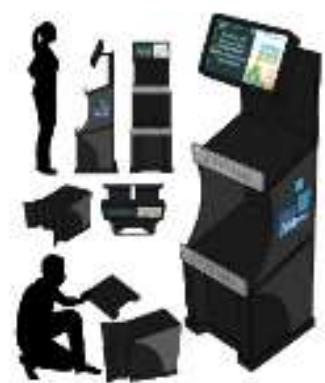

Gambar 7 Alternatif desain terpilih (Sumber : dokumen pribadi)

\section{KESIMPULAN}

\subsection{Kesimpulan}

Kesimpulan dari Penelitian yakni: Perancangan rak yang dapat di bongkar pasang sebagai penyajian buku dapat sangat membantu Penerbit Zifatama dalam menjual bukunya di berinterior seperti acara Pameran dan Seminar sehingga dapat menjadi solusi agar penerbit dapat menjual bukunya tidak harus di toko buku. Selain itu dengan diberikannya media digital informasi pada rancangan dapat memberikan konsumen informasi mengenai buku Penerbit Zifatama lainnya Untuk proses pembuatan produk, terdapat banyak kendala yang disebabkan oleh wabah Covid-19 yang makin meningkat sehingga produk tidak dapat dibuat 1:1 namun dapat dibuat menjadi 1:2 yakni model

\subsection{Saran}

Penelitian Desain Rak Display Portable Untuk Penyajian Studi Kasus Buku Penerbit Zifatama ini masih memiliki banyak kekurangan, diantaranya : Saat mode bongkar tidak terdapat Handle saat membawanya, tampilannya yang kurang eye catching dan masih perlu dipertimbangkannya kembali Bahan atau sistemnya. Harapannya, penelitian ini dikembangkan lagi agar mudah digunakan penerbit 


\section{Daftar pustaka}

1. Nastain, I. Toko Buku di Majalengka Kian Sepi Pengunjung. 2019 [cited 20192 Februari 2019]; Available from: https://daerah.sindonews.com/artikel/jabar/5382/toko-buku-di-majalengka-kian-sepi-pengunjung.

2. $\quad$ Pratiwi, P.S. Minat Baca Masyarakat Indonesia Masih Rendah. 2018 [cited 201827 Maret 2018]; Available from: https://www.cnnindonesia.com/gaya-hidup/20180326160959-282-285982/minat-baca-masyarakat-indonesia-masihrendah.

3. Riyadi, S. Rendahnya Minat Baca Generasi Muda di Era Milenial. 2017 [cited 20175 November 2017]; Available from: https://www.kompasiana.com/pipot/59fe5a841774da746f3b22b2/rendahnya-minat-baca-generasi-muda-diera-milenia.

4. Dimas Nugroho, T. Desain Display Media Interaktif Untuk Museum Lumajang Berbasis Augmented Reality dan Interaksi Gerak Tangan dengan Konsep Futuristik dan Dinasmis. . 2019; Available from: http://ossi.despro.its.ac.id/ rb/detail-ta.php?nolihat=00001384.T.2019.

5. Himawan, W. Desain Produk Display Untuk Penyajian Alat Perkakas di Swalayan Arga Bangunan. Jurusan Desain Produk, . 2019; Available from: https://docplayer.info/186297968-Konsep-desain-produk-display-untuk-penyajianalat-perkakas-di-swalayan-arga-bangunan.html.

6. Sugiyono, Metode Penelitian Pendidikan Pendekatan Kuantitatif. 2011: Jaringpena.

7. $\quad$ Purnomo, H., Antropometri dan Aplikasinya (1 ed.). 2013: Graha Ilmu.

8. Kania. Konsep Rumah Minimalis Modern Yang Harus Kamu Ketahui. 2019 [cited 201927 Februari 2019]; Available from: https://www.dekoruma.com/artikel/81748/konsep-rumah-minimalis-modern. 